\title{
Jumne Seuroscience
}

The Official Journal of

January 1,2001

the Society for Neuroscience

Volume 21 Number 1

Rapid Communications are available online only.

Rapid Communications (http://www.jneurosci.org)

RC118(1-5) Amyloid- $\beta$ Peptides Are Cytotoxic to Oligodendrocytes Jan Xu, Shawei Chen, S. Hinan Ahmed, Hong Chen, Grace Ku, Mark P. Goldberg, and Chung Y. Hsu

RC119(1-4) The Derailed Guidance Receptor Does Not Require Kinase Activity In Vivo Shingo Yoshikawa, Joshua L. Bonkowsky, Michelle Kokel, Stanley Shyn, and John B. Thomas

RC120(1-5) $\beta$-Amyloid ${ }_{1-42}$ Peptide Directly Modulates Nicotinic Receptors in the Rat Hippocampal Slice

D. L. Pettit, Z. Shao, and J. L. Yakel

Editorial Changes for 2001

i Responsible Conduct Regarding Scientific Communication

Society for Neuroscience

\section{Articles}

\section{Cellular/Molecular}

1 A Calcium-Dependent Feedback Mechanism Participates in Shaping Single NMDA Miniature EPSCs

Masashi Umemiya, Nansheng Chen, Lynn A. Raymond, and Timothy H. Murphy

The Cerebellum-Specific Munc13 Isoform Munc13-3 Regulates Cerebellar Synaptic Transmission and Motor Learning in Mice Iris Augustin, Stefan Korte, Michael Rickmann, Hans A. Kretzschmar, Thomas C. Südhof, Jochen W. Herms, and Nils Brose

Nerve Growth Factor, But Not Epidermal Growth Factor, Increases Fra-2 Expression and Alters Fra-2/JunD Binding to AP-1 and CREB Binding Elements in Pheochromocytoma (PC12) Cells

Valerie Boss, John D. Roback, Andrew N. Young, Linda J. Roback, Daniela M. Vogt Weisenhorn, Rafael Medina-Flores, and Bruce H. Wainer

Involvement of the Secretory Pathway for AMPA Receptors in NMDA-Induced Potentiation in Hippocampus

Greg Broutman and Michel Baudry

Characterization of Extracellular Dopamine Clearance in the Medial Prefrontal Cortex: Role of Monoamine Uptake and Monoamine Oxidase Inhibition

Hollie K. Wayment, James O. Schenk, and Barbara A. Sorg

Blockade of NGF-Induced Neurite Outgrowth by a Dominant-Negative Inhibitor of the Egr Family of Transcription Regulatory Factors

Yechiel Levkovitz, Kevin J. O'Donovan, and Jay M. Baraban

The Rpe65 Leu450Met Variation Increases Retinal Resistance Against Light-Induced Degeneration by Slowing Rhodopsin Regeneration

Andreas Wenzel, Charlotte E. Remé, Theodore P. Williams, Farhad Hafezi, and Christian Grimm 
Structure and Dynamics of the GABA Binding Pocket: A Narrowing Cleft that Constricts during Activation

David A. Wagner and Cynthia Czajkowski

Kaspar E. Vogt and Wade G. Regehr

Fornix-Dependent Induction of Hippocampal CCAAT Enhancer-Binding Protein $\beta$ and $\delta$ CoLocalizes with Phosphorylated cAMP Response Element-Binding Protein and Accompanies Long-Term Memory Consolidation

Stephen M. Taubenfeld, Kjesten A. Wiig, Barbara Monti, Bridget Dolan, Gabriella Pollonini, and Cristina M. Alberini

Glucocorticoid Receptor-Mediated Suppression of Activator Protein-1 Activation and Matrix Metalloproteinase Expression after Spinal Cord Injury

Jan Xu, Gyeong-Moon Kim, S. Hinan Ahmed, Jinming Xu, Ping Yan, Xiao Ming Xu, and Chung Y. Hsu

Vitamin D Hormone Confers Neuroprotection in Parallel with Downregulation of L-Type Calcium Channel Expression in Hippocampal Neurons Lawrence D. Brewer, Veronique Thibault, Kuey-Chu Chen, Moises C. Langub, Philip W. Landfield, and Nada M. Porter

Localization and Mechanisms of Action of Cannabinoid Receptors at the Glutamatergic Synapses of the Mouse Nucleus Accumbens David Robbe, Gérard Alonso, Florence Duchamp, Joël Bockaert, and Olivier J. Manzoni

Expression of Brain-Derived Neurotrophic Factor in Cortical Neurons Is Regulated by Striatal Target Area

Josep M. Canals, Núria Checa, Sònia Marco, Peter Åkerud, Alice Michels, Esther Pérez-Navarro, Eduard Tolosa, Ernest Arenas, and Jordi Alberch

The Contribution of Dendritic Kv3 $\mathrm{K}^{+}$Channels to Burst Threshold in a Sensory Neuron Asim J. Rashid, Ezequiel Morales, Ray W. Turner, and Robert J. Dunn

Vaccination for Neuroprotection in the Mouse Optic Nerve: Implications for Optic Neuropathies Jasmin Fisher, Hanna Levkovitch-Verbin, Hadas Schori, Eti Yoles, Oleg Butovsky, Joel F. Kaye, Avraham Ben-Nun, and Michal Schwartz

Presynaptic Role of cGMP-Dependent Protein Kinase during Long-Lasting Potentiation Ottavio Arancio, Irina Antonova, Stepan Gambaryan, Suzanne M. Lohmann, Jason S. Wood, David S. Lawrence, and Robert D. Hawkins,

Independent Anchoring and Assembly Mechanisms of INAD Signaling Complexes in Drosophila Photoreceptors

Susan Tsunoda, Yumei Sun, Emiko Suzuki, and Charles Zuker

\section{Development/Plasticity/Repair}

The External Granule Layer of the Developing Chick Cerebellum Generates Granule Cells and Cells of the Isthmus and Rostral Hindbrain

John C. Lin, Li Cai, and Constance L. Cepko

169 Bcl- $\mathrm{X}_{\mathrm{L}}-$ Caspase-9 Interactions in the Developing Nervous System: Evidence for Multiple Death Pathways

Aliya U. Zaidi, Cleta D’Sa-Eipper, Jennifer Brenner, Keisuke Kuida, Timothy S. Zheng,

Richard A. Flavell, Pasko Rakic, and Kevin A. Roth

An Evolutionarily Conserved Transmembrane Protein That Is a Novel Downstream Target of Neurotrophin and Ephrin Receptors

Haeyoung Kong, Jim Boulter, Janet L. Weber, Cary Lai, and Moses V. Chao 
Functional Plasticity Triggers Formation and Pruning of Dendritic Spines in Cultured Hippocampal Networks

Miri Goldin, Menahem Segal, and Elena Avignone

Age and Gender Predict Volume Decline in the Anterior and Posterior Hippocampus in Early Adulthood

J. C. Pruessner, D. L. Collins, M. Pruessner, and A. C. Evans

Cell-Cycle Kinetics of Neocortical Precursors Are Influenced by Embryonic Thalamic Axons Colette Dehay, Pierre Savatier, Véronique Cortay, and Henry Kennedy

Nerve Injury Induces a Rapid Efflux of Nitric Oxide (NO) Detected with a Novel

NO Microsensor

Shanta M. Kumar, D. Marshall Porterfield, Kenneth J. Muller, Peter J. S. Smith, and

Christie L. Sahley

Developmental Expression of Retinal Cone cGMP-Gated Channels: Evidence for Rapid Turnover and Trophic Regulation

Gladys Y.-P. Ko, Michael L. Ko, and Stuart E. Dryer

\section{Behavioral/Systems}

Expression of Neuronal Connexin36 in AII Amacrine Cells of the Mammalian Retina Andreas Feigenspan, Barbara Teubner, Klaus Willecke, and Reto Weiler

Experience-Dependent Changes in Extracellular Spike Amplitude May Reflect Regulation of Dendritic Action Potential Back-Propagation in Rat Hippocampal Pyramidal Cells Michael C. Quirk, Kenneth I. Blum, and Matthew A. Wilson

Connectional and Architectonic Evidence for Dorsal and Ventral V3, and Dorsomedial Area in Marmoset Monkeys

David C. Lyon and Jon H. Kaas

Enhanced Cortical Extracellular Levels of Cholecystokinin-Like Material in a Model of Anticipation of Social Defeat in the Rat

Chrystel Becker, Marie-Hélène Thiébot, Yvan Touitou, Michel Hamon, François Cesselin, and Jean-Jacques Benoliel

Amygdalar Efferents Initiate Auditory Thalamic Discriminative Training-Induced Neuronal Activity Amy Poremba and Michael Gabriel

Tonic Descending Facilitation from the Rostral Ventromedial Medulla Mediates OpioidInduced Abnormal Pain and Antinociceptive Tolerance

Todd W. Vanderah, Nova M. H. Suenaga, Michael H. Ossipov, T. Philip Malan Jr, Josephine Lai, and Frank Porreca

Temporal Contrast Adaptation in the Input and Output Signals of Salamander Retinal Ganglion Cells

Kerry J. Kim and Fred Rieke

$300 \quad$ Neural Correlates of Auditory-Visual Stimulus Onset Asynchrony Detection Khalafalla O. Bushara, Jordan Grafman, and Mark Hallett

305 Prepulse Inhibition Deficits and Perseverative Motor Patterns in Dopamine Transporter Knock-Out Mice: Differential Effects of D1 and D2 Receptor Antagonists Rebecca J. Ralph, Martin P. Paulus, Fabio Fumagalli, Marc G. Caron, and Mark A. Geyer

Invariance of Angular Threshold Computation in a Wide-Field Looming-Sensitive Neuron Fabrizio Gabbiani, Chunhui Mo, and Gilles Laurent

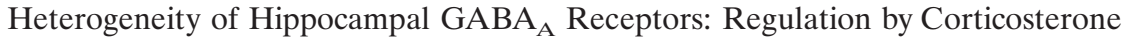
Miles Orchinik, Steven S. Carroll, Yi-Huey Li, Bruce S. McEwen, and Nancy G. Weiland 
356 Retrograde Amnesia for Spatial Memory Induced by NMDA Receptor-Mediated Long-Term Potentiation Vegard Heimly Brun, Kristin Ytterbø, Richard G. M. Morris, May-Britt Moser, and Edvard I. Moser

Cover: BDNF is upregulated by cortical neurons in response to striatal damage. Confocal image of in situ hybridization for BDNF (blue) and immunoreactivity for the NeuN (red) and GFAP (green) show that only neurons upregulated the expression of this neurotrophin. Our results suggest that enhancement of BDNF may be an endogenous trophic response to counteract cortical and/or striatal cell death in a Huntington's disease rat model. For details, see the article by Canals et al. in this issue (pages 117-124).

Persons interested in becoming members of the Society for Neuroscience should contact the Membership Department, Society for Neuroscience, 11 Dupont Circle, NW, Suite 500, Washington, DC 20036, phone 202-462-6688.

Instructions for Authors appear at the end of the January 1, 2001 issue. Copies of the Instructions can be obtained by writing to The Journal of Neuroscience, Society for Neuroscience, 11 Dupont Circle, NW, Suite 500, Washington, DC 20036, phone 202-4626688, fax 202-462-1547, e-mail jn@sfn.org. The Instructions are also available via Internet (http://www.jneurosci.org/misc/itoa.shtml). Rapid Communications Instructions for Authors appear at the end of the January 15, 1999 issue and are also available via Internet (http://www.sfn.org/RapidComm/ifa.html). Submissions should be sent to the above address. Scientific inquiries concerning manuscripts can be made directly to Dr. Gordon M. Shepherd, Editor-in-Chief, The Journal of Neuroscience, Section of Neurobiology, Yale University School of Medicine, 333 Cedar Street, New Haven, CT 06510, phone 203-785-4336, fax 203-785-6990, e-mail jneurosci@yale.edu.

The Journal of Neuroscience requests that authors send a disk containing an electronic file of their manuscript with each submission. Most word processing software can be used; see the Instructions for Authors for detailed guidelines on acceptable disk and file formats. 